\title{
The Zero Flow Performance of a Sing-Around Type Flow Meter
}

\author{
By Dr. Jerker Delsing \\ Dept. of Heat and Power Engineering, Lund Institue of Technology, Sweden
}

\begin{abstract}
Zero flow performance was tested on a new sing-around flow meter design. Design considerations were taken to correct for the speed of sound influences and reciprocity effect. The meter was tested using from 1,000 to 20,000 sing-around loops. To investigate averaging phenomena, 1 100 primary velocity values were averaged to form one velocity value. The temperature range tested was $2-45^{\circ} \mathrm{C}$, with measurements at $5^{\circ} \mathrm{C}$ intervals.

The measurements show a zero flow stability of better than $\pm 0.6 \mathrm{~mm} / \mathrm{s}( \pm 11 / \mathrm{h}, \emptyset 25 \mathrm{~mm}$ pipe) in the entire temperature range. The standard deviation at each temperature tested was less than $0.45 \mathrm{~mm} / \mathrm{s}$. This implies that as low flow velocities as $6 \mathrm{~cm} / \mathrm{s}(100 \mathrm{l} / \mathrm{h}, \emptyset 25 \mathrm{~mm}$ pipe) could be measured with an accuracy of better than $\pm 1 \%$.

The tests were made with water as media but we anticipate equivalent results for other liquids as well as for gases.
\end{abstract}

\section{Introduction}

The accuracy of flow meters are of great importance since the fluid measured by flow meters represents enormous amounts of money. For many applications the accuracy and reliability of commonly used flow metering techniques, such as turbine meter and orifice plate meters, are not sufficient. Thus a search for better flow meters is necessary.

Modern electronic technology has made it possible to devise new flow metering technologies, such as electromagnetic flow meters, Coriolis flow meter and ultrasonic flow meters. These technologies can hopefully fulfill the requirement for accuracy and reliability called for by advanced users in the industry.

New technologies cause new possible errors. Conventional measuring techniques, such as turbine meters, do not have problems with measuring zero flow. However modern technologies, for example Coriolis, ultrasonic and electro- magnetic flow meters, do have problems with zero flow instabilities. This forces us to state accuracy as both an accuracy of measured value relative to actual flow and as absolute stability relative to zero flow. This paper will present zero flow measurements for an ultrasound sing-around flow meter developed at Lund Institute of Technology.

\section{The sing-around flow meter}

For the following discussion we need a brief review of the sing-around method. We will assume a configuration as shown in figure 1.

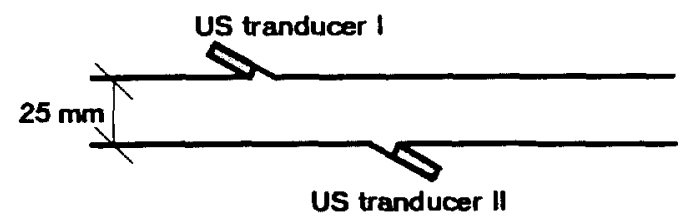

Figure 1. Sing-around flow meter body.

A sing-around loop is started when we transmit a short ultrasound pulse from, say, the upstream positioned transducer. This pulse is received by the downstream transducer. The pulse is fed to the sing-around electronics, which will detect it and immediately start the transmission of the next ultrasound pulse in the same direction, thus establishing a "sing-around" loop. This will " go on for a number of loops. The same procedure is subsequently repeated in the upstream direction. The sing-around loop will oscillate with a certain period, $t$, called the sing-around period. The sing-around period depends on the speed of sound, $c$, of the fluid between the transducers, the transducer distance, $L$, and the fluid velocity, $v$. Thus, we can write the downstream and upstream sing-around periods, $t_{1}$ and $t_{2}$, as:

$$
\dagger_{1}=\frac{L}{c+v^{*} \cos \alpha} \quad \dagger_{2}=\frac{L}{c-V^{*} \cos \alpha}
$$

From the sing-around periods, $t_{1}$ and $t_{2}$, the fluid velocity, $v_{12}$ is easily found as: 
$v_{12}=\frac{L+\cos \alpha}{2}\left(\frac{1}{t_{2}}+\frac{1}{t_{2}}\right)$

To determine the fluid velocity we only need to know the transducer distance, $L$, the interrogation angle $\alpha$, and measure the downstream and upstream sing-around periods, $t_{1}$ and $t_{2}$, respec-

tively. Unfortunately the resolution requirement on the sing-around period measurement is very high. A sing-around period measurement resolution on the order of $1: 10^{7}$ is needed to measure fluid velocities of $5 \mathrm{~cm} / \mathrm{s}$ with accuracies of $1 \%$. For a sing-around period of $64 \mu \mathrm{s}$ this implies an absolute time resolution of about 80 ps, (light travels $25 \mathrm{~mm}$ during that time). This high period measurement resolution is best obtained from a multiple period average measurement over the number of $\mathrm{N}$ sing-around loops.

The tested sing-around flow meter consists of three main parts: the analog part, the multiple period averaging meter and the microprocessor. The analog part is able to start, maintain and control direction of the sing-around loop. The multiple period average meter measures the total time for $\mathrm{N}$ periods of the sing-around signal. Finally the microprocessor reads the period meter and calculates the fluid velocity, using an improved velocity algorithm [1]:

$v=\frac{l}{2}\left(\frac{1}{t_{n}}-\frac{1}{t_{n-1}}+\frac{1}{t_{n-2}}-\frac{1}{t_{n-3}}\right)$

The distance between the transducer is $9.6 \mathrm{~cm}$ and, since the interrogation angle $\alpha$ is $20^{\circ}$ the effective distance of fluid and sound interaction is $9.0 \mathrm{~cm}$. To compensate for reciprocity effects, the output impedance of the transmitter has been adjusted for volt exitation of the transducer. The input impedance of the receiver has been adjusted so that the transducer operates in current mode [2], [3].

\section{Theoretical zero flow performance}

Below the theoretical zero flow performance is calculated for the tested sing-around flow meter. These figures will be compared to experimental data.

With a sound path of $9.6 \mathrm{~cm}$ the sing-around period becomes approximately $64 \mu \mathrm{s}$ assuming a speed of sound of $1500 \mathrm{~m} / \mathrm{s}$. The multiple period averaging meter has a reference clock of 66.66
$\mathrm{MHz}$ frequency. This gives us a single period measurement resolution of $14.99 \mathrm{~ns}$, thus achiving a velocity resolution of $0.1 \mathrm{~m} / \mathrm{s}$, which is not sufficient for a high accuracy flow meter. The resolution can be increased using either the multiple period averaging technique, the averaging of single period measurements or combinations of these techniques.

Assuming that the sing-around frequency and the reference clock frequency is uncorrelated, the multiple period averaging measurement will increase the measurement resolution as:

time measuement resolution $=\frac{t_{\text {ref }}}{N}$

The primary velocity resolution will vary with the number of sing-around loops $\mathrm{N}$ as:

$\Delta v_{p}=\frac{L}{2}\left(\frac{\frac{t_{\text {ref }}}{N}}{t_{1}{ }^{*} t_{2}}\right)$

Averaging of these primary velocity, $v_{p}$, measurements will increase the measurement resolution as:

$\Delta v=\frac{\Delta v_{p}}{\sqrt{n}}$

where $\mathbf{n}$ is the averaged number of primary velocity values. The only drawback for the multiple period averaging technique is a long continuous measuring time for each period measurement. Using excessive time for the measurement of a sing-around period gives possibilities for errors in the velocity measurement, due to speed of sound changes. But using the improved velocity algorithm eq. 3 allows the speed of sound to change during the singaround period measurements [1].

Using the multiple period averaging technique over 1,000 sing-around loops we achieve a theoretical period measurement resolution of 14.9 ps and a primary velocity resolution of 0.18 $\mathrm{mm} / \mathrm{s}$. Adding averaging of primary values further enhanches the theoretical resolution. If it is possible to realise this resolution in a real flow meter it will correspond to the possibility to measure flow velocities of $1.8 \mathrm{~cm} / \mathrm{s}$ with an accuracy of $\pm 0.5 \%$, which is sufficient for most applications. 


\section{Experimental set-up}

The zero flow performances was measured using two main set-ups. First the meter body was mounted in a flow rig. The rig was filled with water and the pipe was closed with valves before and after the sing-around flow meter. The zero flow was measured using the multiple period averaging technique and the improved singaround velocity algorithm to form primary velocity values. Further a number of primary velocity values was averaged to calculate one flow velocity value.

To obtain the best choice of number of singaround loops and how many primary velocity values to average to form one flow velocity value, the tests were made for 1,000 to 20,000 singaround loops and averaging of $1-100$ primary velocity values. Each test produced 1,000 flow velocity values, for which the mean value and the standard deviation were calculated.

The zero flow was also measured with the meter body inserted in a climate chamber. The temperature range tested was $2-45^{\circ} \mathrm{C}$. The temperature was raised from $2-5^{\circ} \mathrm{C}$ and from $5^{\circ} \mathrm{C}$ in $5^{\circ} \mathrm{C}$ intervals up to $45^{\circ} \mathrm{C}$ for each measurement. A zero flow value was measured using 1,000 singaround loops and averaging over 10 primary velocity values. The total time for each measurement varied from $\mathbf{4 5}$ minutes to more than 24 hours, giving from 3,000 to 100,000 velocity values. The mean values and the standard deviation of these values were calculated.

Figure 2 shows the measured zero flow plotted against the number of sing-around loops used for 1and 20 primary velocity values averaged. Figure 2 also shows the standard deviation for the 1,000 flow velocity values measured. Here the mean zero flow velocity values are within $\pm 0.128 \mathrm{~mm} / \mathrm{s}$ and the standard deviation for all measurements is less than $0.17 \mathrm{~mm} / \mathrm{s}$.

In figure 3 we have plotted the measured zero flow velocity for 1000 and 5000 sing-around loops against number of averaged primary velocity values. Figure 4 gives the corresponding standard deviations.

For the measurement with 1,000 sing-around loops the standard deviation is $0.17 \mathrm{~mm} / \mathrm{s}$, i.e. $95 \%$ of all data points are within $\pm 0.17 \mathrm{~mm} / \mathrm{s}$ from the mean value. This should be compared with the theoretical predicted velocity resolution of 0.18 $\mathrm{mm} / \mathrm{s}$, i.e. $\pm 0.09 \mathrm{~mm} / \mathrm{s}$. The reason why we not are able to match the theoretical resolution can probably be found among the following effects:

Acoustic streaming

- Lack of independency between referencs clock and sing-around frequency.

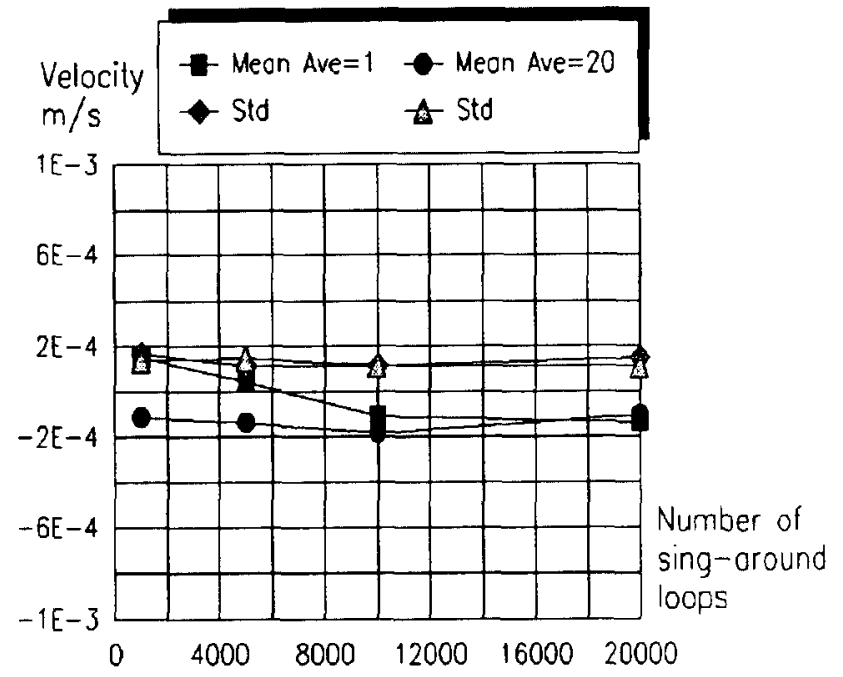

Figure 2. Measured values of mean zero flow velocity averaged over 1,000 samples, together with corresponding standard deviation, for different numbers of primary velocity values averaged verus the number of sing-around loops used.

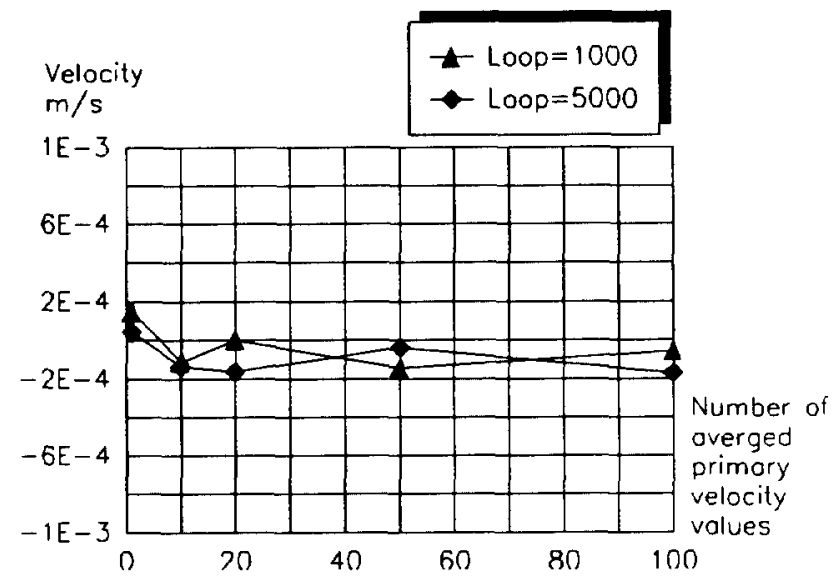

Figure 3. Measured zero flow velocities plotted against number of primary velocity values averaged for measurements using 1,000 and 5,000 sing-around loops. 


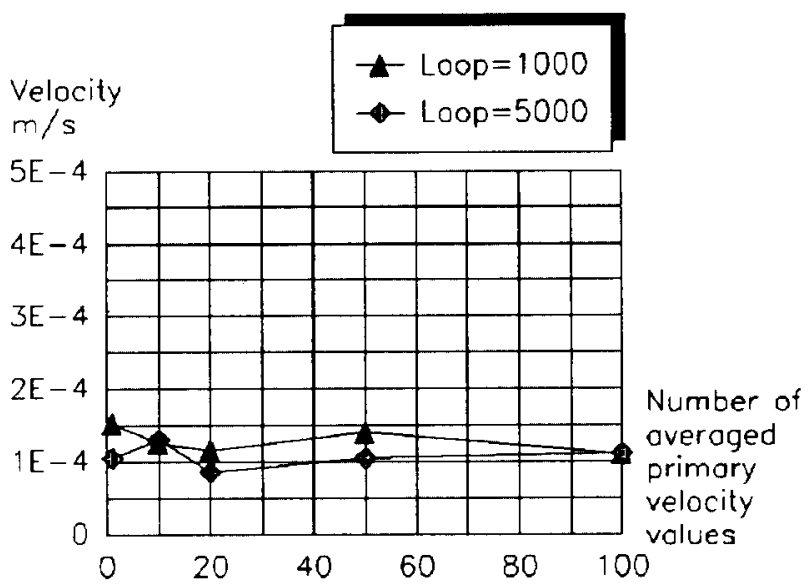

Figure 4. Standard deviations for the measured zero flow velocities shown in figure 3 .

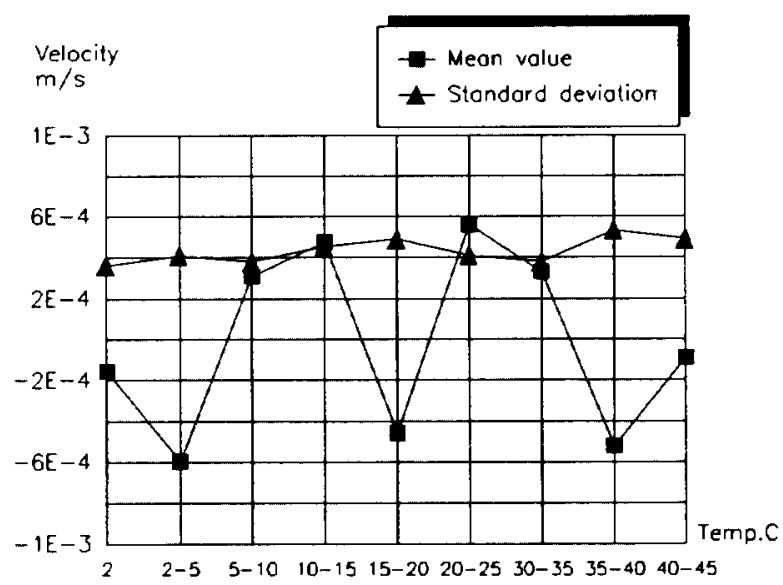

Figure 5. Measured zero flow and its standard deviation plotted against temperature.

With increased number of sing-around loops the standard deviation comes down only slightly and not comparably to the theoretical prediction. The same is found for increased number of primary velocity values averaged. We suggest that using $1,000-5,000$ sing-around loops and an averaging over 10-20 primary velocity values will give the best zero flow performance.

The temperature tests made for every $5^{\circ} \mathrm{Cel}-$ cius gave the zero flow velocity together with associated standard deviations shown in figure 5. The introduction of temperature changes increases the zero flow stability to $\pm 0.6 \mathrm{~mm} / \mathrm{s}$. The standard deviation also increases to $0.4 \mathrm{~mm} / \mathrm{s}$. The reasons for the increase in spread of mean values and in standard devaition can probably be found among the following phenomena:
Thermal influences on ultrasound frequency.

- Convective flow.

Here we do not expect that thermal expansion of the meter body has any significant influence. Measurements where the temperature was changed from 45 to $10^{\circ} \mathrm{C}$ gave a mean value of $0.07 \mathrm{~mm} / \mathrm{s}$ and a standard deviation of $0.4 \mathrm{~mm} / \mathrm{s}$. This indicates that increase in the standard deviation depends on convective flow in the meter body.

\section{Conclusions}

The experimental data shows an overall zero flow accuracy of better than $\pm 0.6 \mathrm{~mm} / \mathrm{s}$, which is a significant improvement over prevously published data. This zero flow stability implies an accuracy of $\pm 1 \%$ for velocities as low as $6 \mathrm{~cm} / \mathrm{s}$, which is sufficient for most industrial applications. Further such stable zero flow performance supports high repeatability which open the possibilities to succesfully apply linearisations of calibrations curves to obtain large metering ranges. Thus, a stable zero flow performance will in the future allow ultrasonic flow meters with a metering range of 1:100.

\section{Acknowledgments}

I like to express my gratitude to Evert Håkansson for his kind help during the work. This research project was sponsored by the Swedish National Energy Administration.

\section{References}

[1] Delsing J., A New Velocity Algorithm for SingAround-Type Flow Meters, IEEE Trans on UFFC, vol. UFFC-34, no. 4, July 1987.

[2] Hemp J.,Theory of Transit time Ultrasonic Flow meters, Journal of Sound and Vibrations, 84(1), pp133-147, 1982.

[3] Sanderson M.L. and Torley B., Error assessment for an intelligent clamp-on transit time ultrasonic flow meter, Proc. of int. conf. on Flow measurement in the mid 80's, June 1986. 